\title{
Effect of Numerous PV Inverters on Power Quality Connected to the Same LV Network in a Suburban Area
}

\author{
G. Gy. Balázs and P. Kiss \\ Department of Electric Power Engineering \\ Budapest University of Technology and Economics \\ Egry Jozsef u. 18. V1 bdg. $3^{\text {rd }}$ floor, H-1111 Budapest (Hungary) \\ Phone/Fax number: +361463 2904, e-mail: balazs.gergely@vet.bme.hu, kiss.peter@vet.bme.hu
}

\begin{abstract}
The number of the domestic power plants is increasing rapidly. Most of these are photovoltaic (PV) systems. It is worth examining the effects of the PV units on the network, because the spreading of these units is expected.

This paper presents a solution how the effect of numerous photovoltaic inverters on the power quality can be simulated and examined if these are connected to the same low voltage (LV) network. The harmonic effect of domestic PV systems is discussed with the application of the so called Double Domain Simulation method. However the distribution network is modelled in the frequency domain, the PV systems are simulated in the time domain. The calculations are performed by different polluted upstream network configuration. Our goal was to build an adequate simulation environment and to examine the effect of numerous PV systems on the power quality of the LV network.
\end{abstract}

\section{Key words}

Power Quality, Harmonics, PV Systems, Computer Simulation, Double Domain Simulation

\section{Brief introduction}

Nowadays the renewable energy supply is increasing rapidly. The electrical energy can be generated dispersedly by domestic power plants, which are becoming more and more widespread. According to the Hungarian standards a power plant is called domestic power plant if it is connected to the low voltage public grid and its power not exceeds $50 \mathrm{kVA}$. These can be connected to the single-phase or the three phase network. Electrical power - that produced by domestic power plant - can be supplied into the public grid or can be used to cover the power demand of a household. In Hungary the Electric Energy Law prescribes that the generated power should be received and transmitted by the distribution system operator (DSO). [1] [5]

The distribution network was built traditionally for oneway distribution, but the spreading of the domestic power plants causes bidirectional electrical energy flow in the distribution network. Moreover the domestic power plants inject harmonic currents into the grid because these systems are connected to the grid through a power electronic device. Therefore these effects raise new problems to the DSO.

The domestic power plant can generate electrical power from wind- solar- or other renewable energy. This research is focusing only on the PV devices. First a simulation environment is described, and then the simulation results are detailed. We assumed that ten PV inverters are connected to the same LV network. We would like to examine the effect of this on the power quality of the LV network. Our research would like to answer the issue of the DSO, what would happen if numerous PV units are installed.

\section{Applied Models}

For the double domain simulation, the distribution network is modelled in the frequency domain, while the PV systems are simulated in the time domain.

\section{A. The model of the distribution system}

The system is based on a real LV transformer zone with overhead wire system from the suburb of Budapest, capital of Hungary. The model has been performed after the layouts of the streets are supplied by the transformer. There are 76 single phase customers are connected to the network through 22 columns. The distribution system is modelled in the frequency domain using the ATPDraw software.

The upstream network is integrated with Thèveninrepresentation. The network's shortcut power is usually around 150 MVA, can be approximated by an inductance (the series resistance can be neglected):

$$
\begin{gathered}
X_{N}=\frac{V_{n}^{2}}{S_{s c}}=\frac{(21 \mathrm{kV})^{2}}{150 \mathrm{MVA}}=2.94 \Omega \\
L_{N}=\frac{X_{N}}{2 \pi f}=\frac{2.94 \Omega}{2 \pi \cdot 50 \mathrm{~Hz}}=9.35831 \mathrm{mH}
\end{gathered}
$$

(where $\mathrm{X}_{\mathrm{N}}$ : network reactance, $\mathrm{V}_{\mathrm{n}}$ : nominal line-to-line voltage, $\mathrm{S}_{\mathrm{sc}}$ : shortcut power, $\mathrm{L}_{\mathrm{N}}$ : network inductance, $\mathrm{f}$ : system frequency) 
The simulations were calculated by different network voltage distortion conditions. The applied voltage spectra can be studied on Table 1 .

Table 1. The voltage spectra

\begin{tabular}{|lrr|}
\hline & \multicolumn{1}{c}{$\begin{array}{c}\text { Ideal } \\
\text { THD }_{\mathbf{V}}=\mathbf{0} \%\end{array}$} & \multicolumn{1}{c|}{ Distorted } \\
\hline $\mathbf{T H D}_{\mathbf{V}}=\mathbf{7 . 8 7 \%}$ \\
\hline $\mathbf{V}_{\mathbf{1}}$ & $12701.71 \mathrm{~V}$ & $12701.71 \mathrm{~V}$ \\
\hline $\mathbf{V}_{\mathbf{3}}$ & $0 \mathrm{~V}$ & $63.51 \mathrm{~V}$ \\
\hline $\mathbf{V}_{\mathbf{5}}$ & $0 \mathrm{~V}$ & $988.72 \mathrm{~V}$ \\
\hline $\mathbf{V}_{\mathbf{7}}$ & $0 \mathrm{~V}$ & $133.81 \mathrm{~V}$ \\
\hline $\mathbf{V}_{\mathbf{9}}$ & $0 \mathrm{~V}$ & $0.0635 \mathrm{~V}$ \\
\hline $\mathbf{V}_{\mathbf{1 1}}$ & $0 \mathrm{~V}$ & $2.45 \mathrm{~V}$ \\
\hline $\mathbf{V}_{\mathbf{1 3}}$ & $0 \mathrm{~V}$ & $0.332 \mathrm{~V}$ \\
\hline $\mathbf{V}_{\mathbf{1 5}}$ & $0 \mathrm{~V}$ & $0.0000635 \mathrm{~V}$ \\
\hline $\mathbf{V}_{\mathbf{1 7}}$ & $0 \mathrm{~V}$ & $0.00607 \mathrm{~V}$ \\
\hline $\mathbf{V}_{\mathbf{1 9}}$ & $0 \mathrm{~V}$ & $0.000822 \mathrm{~V}$ \\
\hline
\end{tabular}

The nominal power of the transformer is $630 \mathrm{kVA}$, the voltage ratio is $21 / 0.4 \mathrm{kV}$. It is modelled by the BCTRAN element of the ATPDraw, where the nominal parameters can be substituted.

The overhead wire system is a $4 * 95 \mathrm{~mm}^{2}$ AASC system, its parameters are given by previous measurements and can be parametered in the frequency domain model of ATPDraw.

The consumers (which are in our case the customers of the DSO) are connected to different phases in order to cause the less asymmetry by the transformer. After the yearly consumption values, all consumers can be represented by its average consumption, which is modelled with a resistance. The whole network can be studied on Fig. 1.

\section{B. The PV system}

Usually the photovoltaic electrical energy converters of the domestic power plants consist of the following parts: photovoltaic panel, DC/DC converter, DC-link, grid tie inverter, input filter block [2]. The photovoltaic panel contains several PV cells connected in series or in parallel. The panel is connected to the DC-link by a $\mathrm{DC} / \mathrm{DC}$ converter. The role of this converter is, to suit the voltage level of the low voltage PV panel to the DC-link. The grid tie inverter can only operate in controlled mode if the DC-link voltage is higher than the peak value of the grid line-voltage. The grid tie inverter is connected to the AC grid through a filter block. A possible structure is represented by Fig.2. that shows the direction of the power flows.

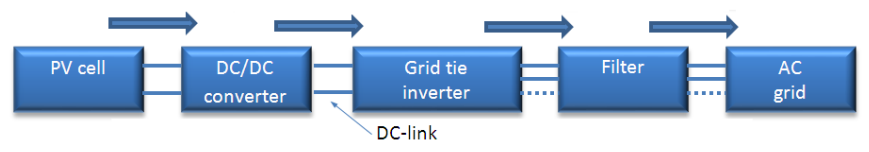

Fig.2. Structure of a PV unit

In this case the DC/DC converter and the grid tie inverter enables unidirectional power flow. These systems are often supplemented with battery storage devices (Fig.3.). Therefore bidirectional power flow should be ensured by the grid-tie inverter, the battery should be charged by the grid.

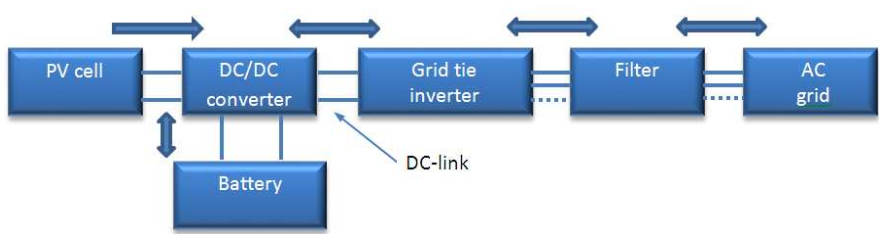

Fig.3. Structure of a PV unit with battery

Our PV system model takes into account the DC/DC converter and the PV cells as a current generator. In the simulation the grid tie converter was modeled as a bridge-type converter that enables bidirectional power flow (Fig.4,5). T-type LCL filters were connected between the inverters and the grid to eliminate the current harmonics (Fig.6.). In our work we examined single- and three-phase grid connected PV inverters. At the singlephase grid connected devices we assumed that the generated power is $1 \mathrm{~kW}$ or $2 \mathrm{~kW}$, while at three-phase connected case we assumed $5 \mathrm{~kW}$.

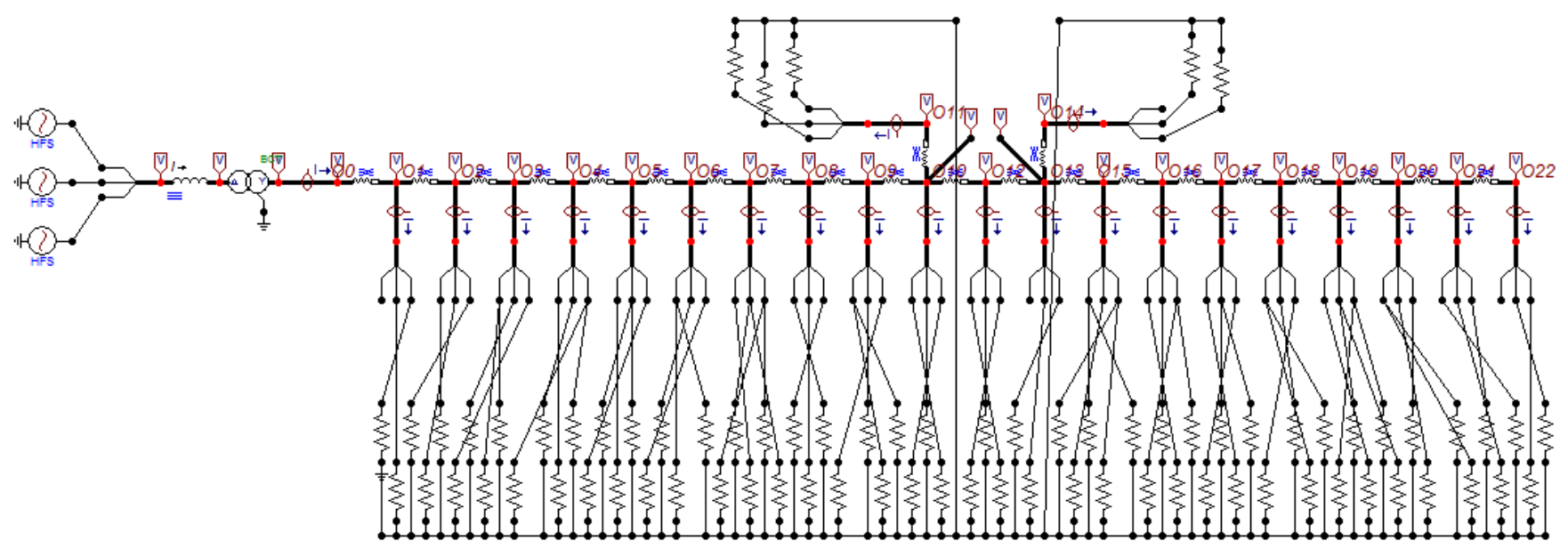

Fig. 1. The model of the examined street 


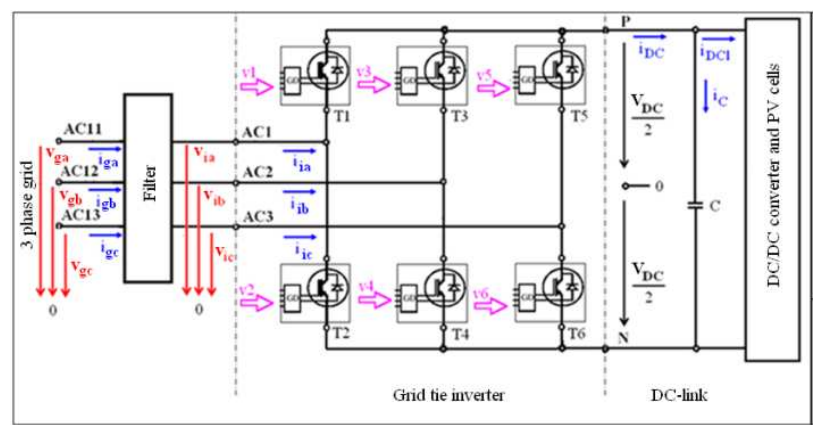

Fig.4. Schematic circuit diagram of a three-phase connected, bridge-type grid tie PV inverter

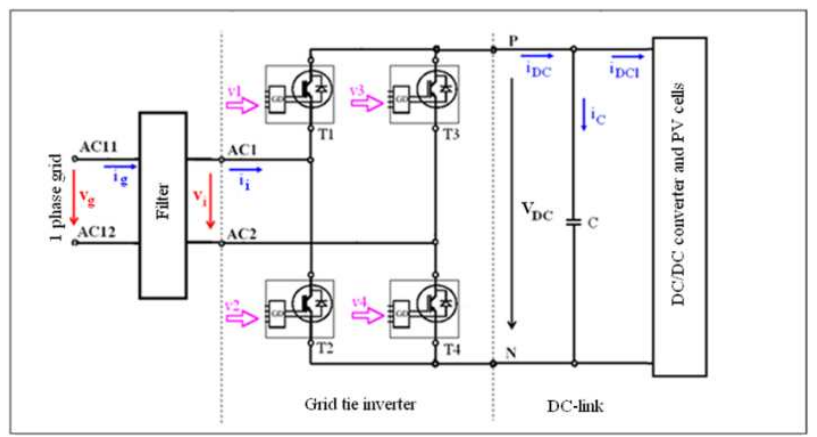

Fig.5. Schematic circuit diagram of a single-phase connected, bridge-type grid tie PV inverter

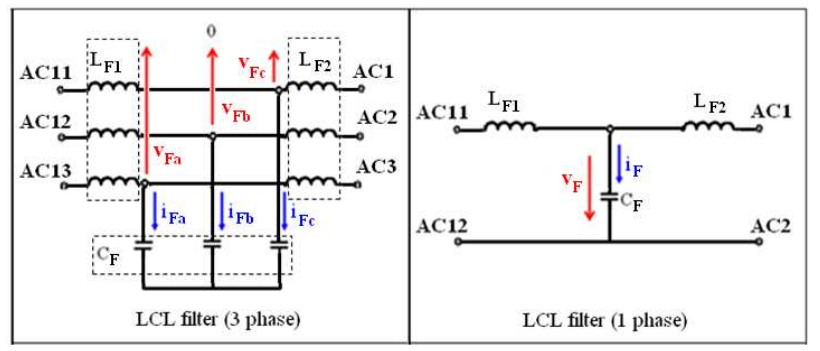

Fig.6. LCL filters for three- and single-phase connected grid tie $\mathrm{PV}$ inverter

We built up the models of the single and the three phase grid tie PV inverter in the time domain in the environment of Matlab Simulink. The inverter models consist of two main parts: the model of the power electronic circuit and the model of the control circuit. The three-phase grid connected units was modelled with Park vectors.

Based on the schematic circuit diagrams (Fig.4,5,6), the following differential equations can be written. (The overlines represent Park vectors, " $1 \mathrm{ph} / 3 \mathrm{ph}$ ": equation of single/three-phase connected circuits.) [3,4]:

- The equation of the LCL filter:

$1 \mathrm{ph}$ :

$$
\begin{aligned}
v_{g}=L_{F 1} \frac{d i_{g}}{d t}+v_{F}, & \bar{v}_{g}=L_{F 1} \frac{d \bar{\imath}_{g}}{d t}+\bar{v}_{F} \\
i_{g}=i_{F}+i_{i}, & \bar{\imath}_{g}=\bar{\iota}_{F}+\bar{\iota}_{i} \\
i_{F}=C_{F} \frac{d v_{F}}{d t}, & \bar{\imath}_{F}=C_{F} \frac{d \bar{v}_{F}}{d t} \\
v_{i}=v_{F}-L_{F 2} \frac{d i_{g}}{d t}, & \bar{v}_{i}=\bar{v}_{F}-L_{F 2} \frac{d \bar{\imath}_{g}}{d t}
\end{aligned}
$$

- The power equations, can be written for both sides of a grid tie converter (lossless converter assumed)

1ph: $p_{i}=p_{D C} \Rightarrow v_{i} \cdot i_{i}=v_{D C} \cdot i_{D C}$

$3 \mathrm{ph}: p_{i}=p_{D C} \Rightarrow 3 \bar{v}_{i} \cdot \bar{l}_{i}=v_{D C} \cdot i_{D C}$

- The current of the DC-link:

$$
i_{D C}=i_{C}+i_{D C l}
$$

- The current of the buffer capacitor:

$$
i_{C}=C \frac{d v_{D C}}{d t}
$$

To fulfil the requirements of network-friendly equipments, the grid tie inverters need to have an adequate control circuit. In our study it was equipped with a cascade control (Fig.7,8.). This structure is commonly used $[2,3,4]$. The primary control loop of the cascade is a DC-voltage-control $\left(\mathrm{v}_{\mathrm{DC}}\right)$ and the secondary loop is grid currents $\left(i_{\mathrm{ga}}, i_{\mathrm{gb}}, \mathrm{i}_{\mathrm{gc}}\right)$ control. This structure guarantees a high power factor and an adequate grid current shape. The grid tie PV inverters were operated by pulse width modulation (PWM) units. In the control circuit the synchronization signal generator produces the fundamental of the grid voltage at the points of common coupling (PCC). Therefore the inverters are operated with sinusoidal current reference signal. The single-phase connected inverters were operated by alternative PWM, because the current ripples can be reduced with this modulation technique.

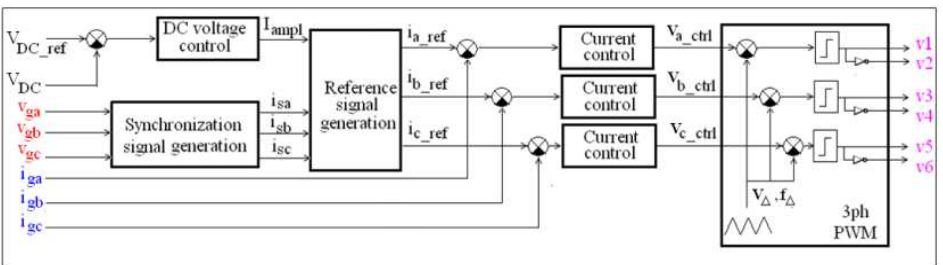

Fig.7. Control circuit block diagram of a three-phase grid connecter inverter

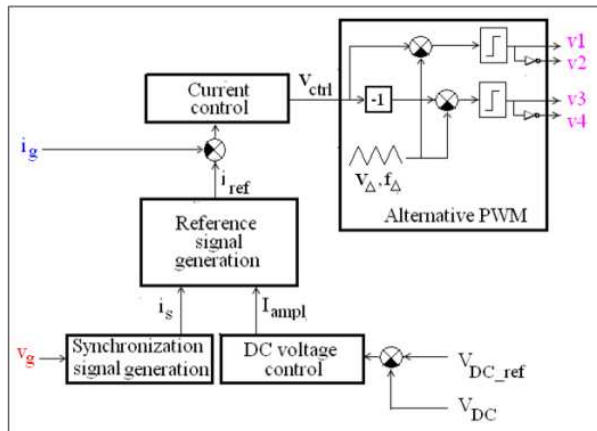

Fig.8. Control circuit block diagram of a single-phase grid connecter inverter

Table 2. represents the applied quantities of the grid tie inverter. Each unit was connected to the same $230 / 400 \mathrm{~V}$ LV voltage network; therefore the nominal voltage peak value of the phase voltage is $325.27 \mathrm{~V}$. At the singlephase connected inverters, the DC voltage level was set to $390 \mathrm{~V}$, while at three-phase connected inverters it was set to $650 \mathrm{~V}$. Relatively low switching frequency was selected $(4500 \mathrm{~Hz})$, higher frequency would enable lower LCL filter. During the simulations we assumed that the PV inverters generated the nominal current into the grid. 
Table 2: Quantities applied in the PV models

\begin{tabular}{|ccccc|}
\hline \multicolumn{5}{c|}{ Quantities } \\
& $1 \mathrm{ph} 1 \mathrm{~kW}$ & $1 \mathrm{ph} 2.5 \mathrm{~kW}$ & $3 \mathrm{ph} 5 \mathrm{~kW}$ \\
\hline $\mathbf{V}_{\mathbf{g} \text { nominal }}$ & \multicolumn{5}{c|}{325.2691} \\
\hline $\mathbf{I}_{\text {nominal }}$ & 6.15 & 15.37 & 10.21 & $\mathrm{~A}$ \\
\hline $\boldsymbol{\omega}$ & & $314.1593(2 \pi 50 \mathrm{~Hz})$ & & $1 / \mathrm{sec}$ \\
\hline $\mathbf{L}_{\mathbf{F 1}}$ & 2 & 2 & 4 & $\mathrm{mH}$ \\
\hline $\mathbf{C}_{\mathbf{F}}$ & 0.361 & 2.26 & 2.10 & $\mu \mathrm{F}$ \\
\hline $\mathbf{L}_{\mathbf{F} 2}$ & 5 & 0.8 & 2 & $\mathrm{mH}$ \\
\hline $\mathbf{V}_{\mathbf{D C} \_ \text {ref }}$ & 390 & 390 & 650 & $\mathrm{~V}$ \\
\hline $\mathbf{C}$ & 253 & 632 & 90 & $\mu \mathrm{F}$ \\
\hline $\mathbf{f}_{\Delta}$ & & 4500 & & $\mathrm{~Hz}$ \\
\hline
\end{tabular}

\section{Simulation}

Different modelling technologies could be investigated for modelling the harmonic current and voltages along the network:

The easiest way is the simplified model where the whole model is in the frequency domain. In this case the current spectra of the time dependent elements (the PV inverters) should be determined previously, thus the interaction between the network and the inverters cannot be studied. [6]

It would be possible to compose a sophisticated model working in the time domain, but the parameters of the network are given in the frequency domain, and the conversion would result very difficult transfer functions. [6]

This chapter gives a short overview on the calculation results made by the application of Double Domain Simulation method, which is using the combination of the two domains.

\section{A. The Double Domain Simulation method}

The current spectra of the PV inverters are in function of the distorted supply voltage. Because the voltage distortion is caused partly by the PV inverters, an iteration algorithm was developed to convert the variables between the time and frequency domain vice and verse. This method is called to double domain simulation (Fig 9.), it was published for a railway network in some previous conferences in papers $[6,7,8]$.

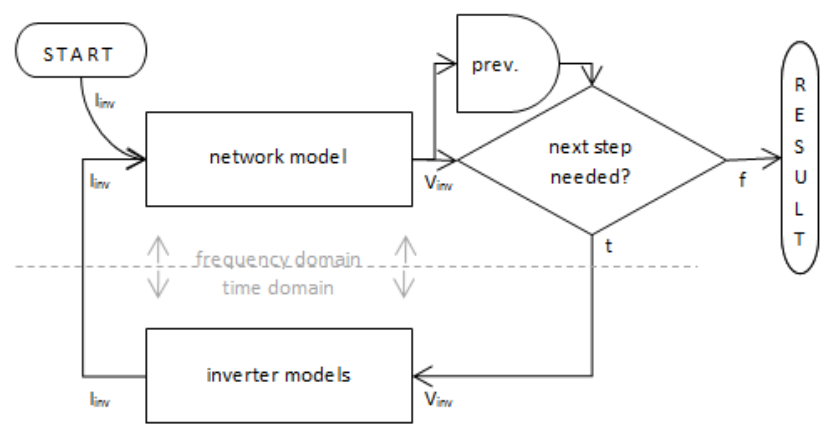

Fig. 9. Double domain simulation method

\section{B. Locations of the PV inverters}

In reality, there are 22 PCC's in the transformer area (Fig.1.), where we were calculating with $10 \mathrm{PV}$ systems. The locations of the PV inverters - at different PCCs were randomly selected and presented in Table 3 . The PV inverters were considered as fundamental and harmonic current generators. Therefore, the model in Fig. 1 - that represents the real conditions - was modified, at proper PCCs, where PV inverters were assumed, the resistors were replaced with current generators. The following subchapter describes, how the generated current of the PV inverters were calculated.

Table 3: Locations of the PV units along the LV network

\begin{tabular}{|ccc|}
\hline $\begin{array}{c}\text { PCC locations of } \\
\text { the PVs }\end{array}$ & Phase & $\mathbf{P}_{\mathbf{n}}$ (nominal power) \\
\hline $\mathbf{3 .}$ & $\mathrm{a}$ & $1 \mathrm{~kW}$ \\
\hline $\mathbf{6 .}$ & $\mathrm{c}$ & $1 \mathrm{~kW}$ \\
\hline $\mathbf{7 .}$ & $\mathrm{b}$ & $2.5 \mathrm{~kW}$ \\
\hline $\mathbf{8 .}$ & $\mathrm{a}, \mathrm{b}, \mathrm{c}$ & $5 \mathrm{~kW}$ \\
\hline $\mathbf{9 .}$ & $\mathrm{a}$ & $2.5 \mathrm{~kW}$ \\
\hline $\mathbf{9 .}$ & $\mathrm{b}$ & $2.5 \mathrm{~kW}$ \\
\hline $\mathbf{1 1}$. & $\mathrm{a}, \mathrm{b}, \mathrm{c}$ & $5 \mathrm{~kW}$ \\
\hline $\mathbf{1 5 .}$ & $\mathrm{c}$ & $2.5 \mathrm{~kW}$ \\
\hline $\mathbf{2 0 .}$ & $\mathrm{a}$ & $2.5 \mathrm{~kW}$ \\
\hline $\mathbf{2 2}$. & $\mathrm{b}$ & $2.5 \mathrm{~kW}$ \\
\hline
\end{tabular}

\section{Simulation process and examined cases}

At the beginning of the simulation process, characteristic resistances of the PV inverters were defined based on their fundamental nominal current and the fundamental grid voltage. Then these values were substituted into the model of the network (Chapter 2.A). After it, the ATPDraw software calculated the voltage spectra of each PCC. Based on the voltage spectra, voltage time functions could be defined that were the inputs of the time domain simulation. The ten PV inverter models (Chapter 2.B) received these voltage time functions $\left(\mathrm{v}_{\mathrm{g}(\mathrm{a}, \mathrm{b}, \mathrm{c})}\right.$ in Fig.4,5), and the Matlab software was calculating until the currents $\left(i_{g(a, b, c)}\right.$ in Fig.4,5) reached the steady-state. These current responses are a function of time, whereby the current spectra could be defined. These current spectra became the input of the frequency domain network model. These steps followed each other until the differences between the steps did not become less than a predefined small value $(1 \%)$. This circulation process can be followed in Fig.9. The results of the process were the current spectra of the PV inverters, and the $\mathrm{THD}_{\mathrm{I}}$ values calculated by the spectra.

Calculations were performed for two cases: at first we assumed that the upstream network possessed ideal sinusoidal voltage, and then we examined the system by setting distorted voltage on the upstream network (Table 1.). We calculated the current spectra of the PV inverters in both cases, while LCL filters or only L filters were connected between the converters and the grid. When $\mathrm{L}$ filters were examined, $\mathrm{L}_{\mathrm{F} 2}=\mathrm{C}_{\mathrm{F}}=0$ was assumed. 


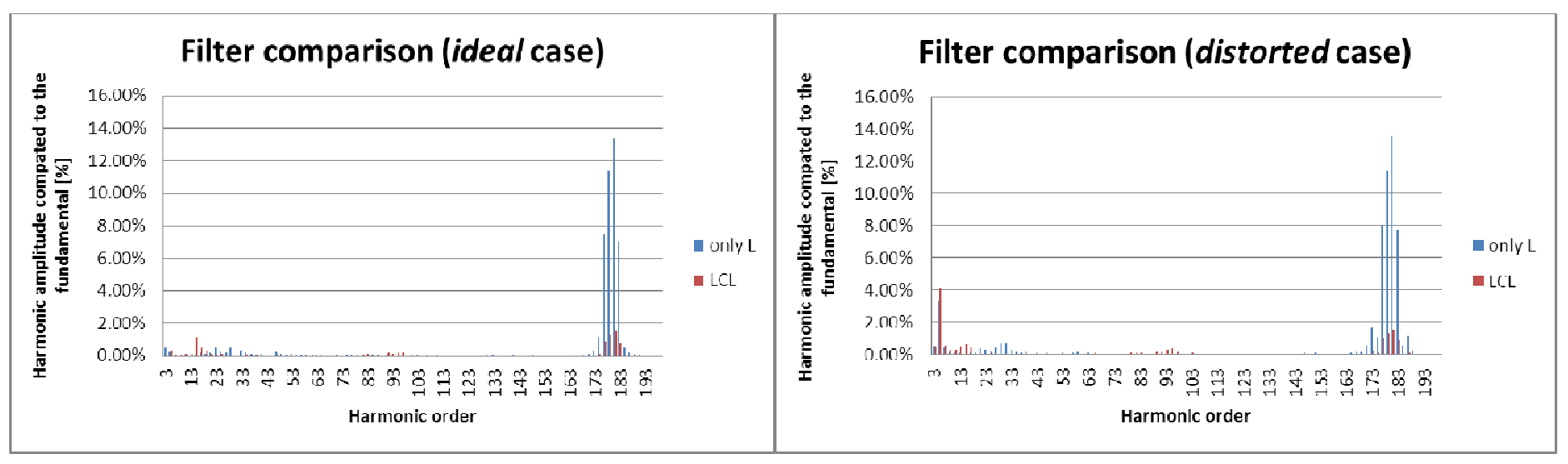

Fig. 10. Filter current spectra comparison, while the upstream network voltage ideal sinusoidal or distorted.

\section{Simulation results}

We received approximately the same results, Fig.10. represents the current spectra of a selected single-phase connected PV inverter ( $9^{\text {th }}$ PCC, 'b' phase connected $)$. At alternative PWM the current harmonics appear at $2 \mathrm{f}_{\Delta} \pm \mathrm{f}_{1} \pm 3 \mathrm{f}_{1} \ldots \quad\left(\mathrm{f}_{1}\right.$ : fundamental frequency). [9,10] The results meet the requirements because current harmonics can be observed at the around the $180^{\text {th }}$ order $\left(2 \mathrm{f}_{\Delta}=9 \mathrm{kHz} \rightarrow 180^{\text {th }}\right)$. According to the figure, PWM generated high-frequency harmonics can be reduced by well-tuned LCL filter.

Fig. 10. also shows that the low frequency harmonics of the grid voltage can be observed in the inverter current, but with low amplitude. These harmonic components are well-damped by both the L and the LCL filter.

Table 4: Simulation results: $\mathrm{THD}_{\mathrm{I}}$ values

\begin{tabular}{|c|c|c|c|c|}
\hline \multirow{2}{*}{ PCC } & \multirow{2}{*}{ phase } & \multirow{2}{*}{$\mathbf{P}_{\mathbf{n}}$} & THD $_{\text {I }}$ & THD $_{\text {I }}$ \\
\hline & & & ideal & distorted \\
\hline 3 & $\mathrm{a}$ & $1 \mathrm{~kW}$ & $0.98 \%$ & $3.80 \%$ \\
\hline 6 & $\mathrm{c}$ & $1 \mathrm{~kW}$ & $1.00 \%$ & $4.31 \%$ \\
\hline 7 & b & $2.5 \mathrm{~kW}$ & $1.13 \%$ & $2.89 \%$ \\
\hline \multirow{3}{*}{8} & $\mathrm{a}$ & \multirow{3}{*}{$5 \mathrm{~kW}$} & $2.28 \%$ & $3.25 \%$ \\
\hline & $\mathrm{b}$ & & $2.33 \%$ & $3.24 \%$ \\
\hline & $\mathrm{c}$ & & $2.22 \%$ & $4.52 \%$ \\
\hline 9 & $\mathrm{a}$ & $2.5 \mathrm{~kW}$ & $1.32 \%$ & $4.72 \%$ \\
\hline 9 & $\mathrm{~b}$ & $2.5 \mathrm{~kW}$ & $1.44 \%$ & $4.18 \%$ \\
\hline \multirow{3}{*}{11} & $\mathrm{a}$ & \multirow{3}{*}{$5 \mathrm{~kW}$} & $2.20 \%$ & $3.36 \%$ \\
\hline & $\mathrm{b}$ & & $2.26 \%$ & $3.27 \%$ \\
\hline & $\mathrm{c}$ & & $2.27 \%$ & $4.66 \%$ \\
\hline 15 & $\mathrm{c}$ & $2.5 \mathrm{~kW}$ & $1.01 \%$ & $4.44 \%$ \\
\hline 20 & $\mathrm{a}$ & $2.5 \mathrm{~kW}$ & $0.87 \%$ & $4.69 \%$ \\
\hline \multirow[t]{2}{*}{22} & $\mathrm{~b}$ & $2.5 \mathrm{~kW}$ & $0.85 \%$ & $4.17 \%$ \\
\hline & & THD $_{\text {I,max }}$ & $2.33 \%$ & $4.72 \%$ \\
\hline
\end{tabular}

Table 4. represents the $\mathrm{THD}_{\mathrm{I}}$ values, that were calculated from the simulation results of each PV inverter current spectra, equipped with LCL filter. According to the table under distorted grid voltage conditions, the standards can be fitted by a properly developed filter.

\section{Conclusions}

The distortion of the grid voltage influences the distortion of the currents generated by the PV inverters, the dominant voltage harmonics appear in the current, although their amplitude is relatively low. We could only examine this effect with the double domain simulation method, because the influence of the grid voltage and the inverter currents could be observed with it. Efficient filters in the power circuit and well-functioning current reference signal generators can reduce the harmonics of the inverter current but these could not be totally eliminated.

In the Hungarian standards [11] there are limitations only for the low frequency harmonics (up to 63th harmonic order), but it would be useful to investigate effort in examining and limiting the higher frequency harmonics, that are injected by the PWM controlled inverters. These current components infect e.g. power line communication (PLC) devices, smart metering devices. In our research the amplitude of these current harmonic components could reach $1 \mathrm{~A}$, although this value is depending on the switching frequency and the filter. Therefore, in order to improve the power quality, it is worth to install an adequate LCL filter.

In our simulation we applied a given LV network, and PV inverters with predefined quantity parameters, but different network installation, or other PV inverter structures can also be examined with our simulation environment. The environment enables examining different filtering methods, in the future we would like to dealing with this issue.

\section{References}

[1] Z. Liszi, "Family House Fed by Solar Energy", in Journal Elektrotechnika, Vol 05/2012, pp21-23. (in Hungarian)

[2] A. Balogh, "Efficiency Increasing Strategies for Converters of Renewable Energy Sources" PhD dissertation, BUTE, Budapest, Hungary (2011) 
[3] G. Gy. Balázs, "Controlling of Four-Quadrant Converters Especially in Electric Vehicles" PhD dissertation, BUTE, Budapest, Hungary (2012)

[4] G. Gy. Balázs, I. Schmidt, and M. Horváth, "Analytical and Simulation Comparisom of Sinusoidal and Resistive modulation Strategies for Network-Friendly Three-Phase Grid-Connected Inverters" in Journal Periodica Polytechnica-Electrical Engineering, Vol 55/2011, pp. 11

[5] A. Dán, T. Tersztyánszky and Gy. Varjú, “ Power Qualty, Budapest, Hungary, Invest-Marketing Ltd. (2006), book in Hungarian

[6] A. Dán, P. Kiss, "Advanced Calculation Method for Modeling of Harmonic Effect of AC High Power Electric Traction", $12^{\text {th }}$ International Conference on Harmonics and Quality of Power, Cascais, Portugal, $1^{\text {st }}-5^{\text {th }}$ Oct, 2006.

[7] A. Dán, P. Kiss, "Effect on Power Quality of the High Power Electric Traction (Double Domain Computer Simulation vs. Site Measurements)", International Conference on Renewable Energies and Power Quality 2006, Palma de Mallorca, Spain $5^{\text {th }}-7^{\text {th }}$ Apr, 2006.

[8] G. G. Balázs, P. Kiss, M. Horváth, I. Schmidt, "Application of the Double Domain Simulation in Comparison of New Current Control Methods for PWM Controlled AC Electric Locomotives", $15^{\text {th }}$ International Conference on Harmonics and Quality of Power, Hong Kong, China, $17^{\text {th }}-20^{\text {th }}$ June, 2012.

[9] D. Grahame Holmes, Thomas A.Lipo: Pulse Width Modulation For Power Converters. USA: IEEE Press, 2003.

[10] F. Jenni, "Steuerverfahren für selbstgeführte Stromrichter" Zurich, Switzerland (1995), ISBN 3519061767.

[11] MSZ EN 50160 standard 